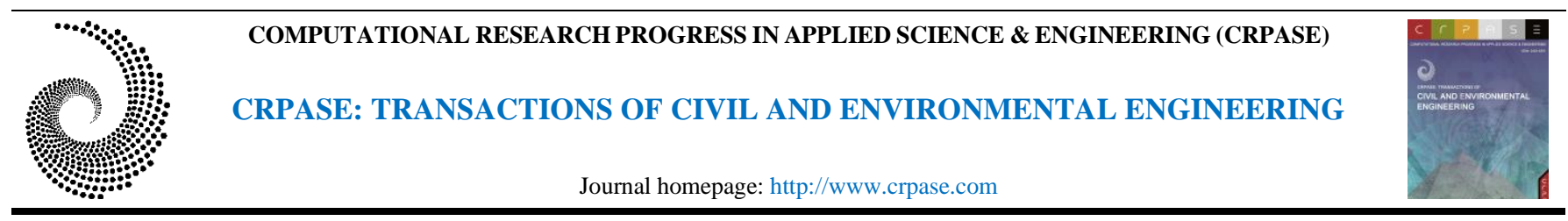

CRPASE: Transactions of Civil and Environmental Engineering 8 Article ID: 2229, 1-6, Special Issue: NCTT 2021

ISSN 2423-4591

Research Article

\title{
Using Decision-making Methods to Prioritize the Construction of Public Transportation Special Routes (Case Study: Rasht)
}

\author{
Seyed Amir Saadatjoo ${ }^{1 *}$, Maziar Abolfazlzadeh ${ }^{2}$, Hassan Ziari ${ }^{1}$, Barat Mojaradi ${ }^{1}$ \\ ${ }^{1}$ School of Civil Engineering, Iran University of Science and Technology (IUST), Tehran, Iran \\ ${ }^{2}$ Department of Civil Engineering, Islamic Azad University North Tehran Branch, Tehran, Iran
}

\begin{tabular}{ll}
\hline Keywords & Abstract \\
\cline { 2 - 3 } $\begin{array}{l}\text { Route Prioritization, } \\
\text { BRT System, }\end{array}$ & $\begin{array}{l}\text { Public transportation is always one of the most significant types of transportation modes. } \\
\text { Fuzzy Hierarchical } \\
\text { Analysis, }\end{array}$ \\
Any weakness in the bus transportation systems and not providing the necessary \\
infrastructure will lead to an increase in traffic junctions. Large and populated cities such as \\
Rasht, in addition to the normal taxi and bus systems, need transportation modes with the \\
ability to move more passengers. The aim of this study is to investigate the possibility of \\
locating the Bus Rapid Transit (BRT) systems in the streets of Rasht. Therefore, by \\
examining different parameters and using different methods, the possibility of implementing \\
BRT lanes is examined. In this study, the information of the bus fleet, comprehensive traffic \\
plan and other demographic information of Rasht city were examined using fuzzy \\
hierarchical analysis methods. based on the results of the analysis, the first priorities for the \\
construction of special lines for BRT lanes were identified.
\end{tabular}

\section{Introduction}

Today, due to the expansion of cities and the rapid growth of urbanization, cities as a place of accumulation of facilities, are known as the main centers of population attraction that the continuation of this trend will cause population density to increase. On the other hand, one of the major problems in big cities is traffic. The issue of intercity transportation systems has long gone beyond the technical and engineering limits and has become a social and economic issue that can have different consequences for a community .Both for asphalt issues and for traffic issues [1]. Long traffic queues, lack of parking, overcrowding, traffic restrictions in the city center, psychological effects, air pollution, etc. are some of the things that have made transport managers and planners more inclined to develop mass public transportation systems and that is why the need to use the public transport system has already been considered more than before [2]. The public transportation system, the most important of which are buses and subways, plays a very important role in the daily movement of passengers in cities and includes many benefits that directly and indirectly affect the quality of daily life of people. From an economic point of view, public transportation is a cheaper option than using a private car. However, in many provinces of our country, the bus system has not been very efficient so far, and many management methods such as allocating special routes, regular bus schedules, etc. that are needed to increase the efficiency of this system have not been fully considered. Especially because of the importance of travel time and the amount of traffic delays in traffic congestion in the cities [3]. However, if the potential capacity of the bus system is used properly, up to half of the intra-city public transport demand can be covered, which will decrease the use of private cars. One of the weaknesses of public transportation systems is the lack of correct distribution of their networks in the city, or in other

\footnotetext{
* Corresponding Author: Seyed Amir Saadatjoo

E-mail address: amir.saadatjoo@gmail.com
}

Received: 14 November 2021; Revised: 13 December 2021; Accepted: 11 January 2022

https://doi.org/10.52547/crpase.8.2229

Academic Editor: Mahdi Feizbahr

Please cite this article as: S. A. Saadatjoo, M. Abolfazlzadeh, H. Ziari, B. Mojaradi, Using Decision-making Methods to Prioritize the Construction of Public Transportation Special Routes (Case Study: Rasht), Computational Research Progress in Applied Science \& Engineering, CRPASE: Transactions of Civil and Environmental Engineering 8 (2022) 1-6, Article ID: 2229. 
words, the lack of proper location of their routes and stations. Therefore, in this study, the aim is to correctly locate the BRT lanes in Rasht.

\section{2. literature Review}

A review of studies on special bus routes and public transportation shows that several methods have been proposed to evaluate and rate these systems. In recent years, the importance of factors affecting the issue of satisfaction has been considered by researchers. Several factors affect the travel time and consequently the number of stations in the public transport system, each of which or a combination of these factors can be studied by researchers.

Levinson by analyzing the factors affecting travel time in American cities showed that in order to maintain the proper functioning of a public transportation system, additional stations should be eliminated to reduce travel time as much as possible [4]. Since passengers tend to minimize time spent outside the vehicle to reach their destination, and transportation organizations tend to reduce their operating costs as much as possible, Saka presented a mathematical model that tried to balance the demands of the bus system users with the transportation organization and showed that proper location between stations can simultaneously reduce the time distance between buses and travel time by considering the limited capacity of the fleet [5]. Bin Yu et al. presented a two-level programming model to optimize the number of buses on the route. This model determines the optimal number of buses with the aim of minimizing the total travel time of passengers by considering the limitations in the total capacity of the fleet. The results showed that this optimization process can increase the $\operatorname{LOS}^{1}$ of a local bus company and the proper integration of several companies can improve the LOS of the transportation system [6]. Assarzadegan et al. using the $\mathrm{AHP}^{2}$ multi-criteria decisionmaking technique optimized the BRT stations' location using the spatial information system and TOPSIS technique. The aim of this study was to reduce public transportation costs and consequently reduce the use of private cars[7]. Rastbod et al. modeled a hypothetical transportation network using a multi-objective genetic algorithm and located the stations by considering the hypothetical population distribution at peak hours. it was concluded that at peak hours, the model tends to increase the number of stations as much as possible [8]. Abedi introduced the technology of big data and using GPS data analysis and extracting hidden travel patterns to optimally locate bus stations. The results show the desired quality and speed of the algorithm [9]. Varesi et al. solved the problem of locating bus stations in the city of Khorramabad using network analysis model (ANP) and fuzzy logic model to analyze the data [10]. Jamili and Pourseyed Aghaee presented the method of eliminating stations using a robust optimization model as a new method in determining the number of urban train stations. In this study, they optimize the number of city train stations by presenting a robust mathematical model and using two Metaheuristic algorithms [11].

\section{Methodology}

By reviewing the available resources in the discussion of model presentation and measuring the strengths and weaknesses of evaluation models, the model used in this study is derived from a combined method Fuzzy - AHP. The traditional AHP model is based on judgment and selection of a 9-degree value in pairs. However, the use of expert opinions alone can not compare the criteria well [12]. Therefore, the use of fuzzy numbers with an uncertainty approach can increase the efficiency and validity of the proposed model. The Fuzzy-AHP model was first proposed with the aim of determining the significance coefficient of an alternative based on multiple criteria. One of the significant advantages of this technique is the use of a combination of qualitative and quantitative data in creating a logical approach [13].

The method of determining the prioritization model is that after determining the weight of each goal, the indicators affecting that goal are measured and the weight and importance of each indicator for the relevant goal is determined by hierarchical analysis. Finally, after determining the weight of each index, sub-indices are defined for each index and a hierarchical analysis is performed between the existing sub-indices and the weight of each sub-index is also determined. Thus, the final model has the ability to determine the position and system of evaluation and prioritization for budget allocation and planning. The final evaluation model is as follows:

$$
\mathrm{BSIP}=\sum_{\mathrm{J}=1}^{\mathrm{m}} \sum_{\mathrm{I}=1}^{\mathrm{n}} \mathrm{W}_{\mathrm{J}}\left(\mathrm{F}(\mathrm{x}) \times \mathrm{W}_{\mathrm{I}}\right)
$$

That in this equation, BSIP is prioritization of correction of accident prone sections, $\mathrm{W}_{\mathrm{J}}$ is the weight of each target in the evaluation pattern, $\mathrm{W}_{\mathrm{I}}$ is the weight of the index for each target and $F(x)$ is the value of the index normalized by the fuzzy function.

The present study is conducted in Rasht, which is one of the metropolises of Iran and the capital of Gilan province. In this research, different quality indicators of Rasht bus system such as travel demand, fleet performance speed, passenger waiting time, fleet life during different years are examined. In order to evaluate the performance of the bus system for the present study based on datum in 2019, the census was conducted on Wednesday (which was a working day and schools were open) from 6:30 A.M to 10:30 P.M. A total of 33 buses were active in the bus organization, of which 30 were used to transport passengers. In each bus, one person was present to record the travel demand, the volume of entry and exit to each bus at each station, the travel time and the operating speed between different stations and other important parameters.

\section{Results and Discussion}

In this section, the effective parameters on the BRT lane, which are in fact the Alternatives in Expert Choice software, are examined. Each of these indicators is evaluated separately for each of the corridors. According to the studies

\footnotetext{
${ }^{1}$ Level of Service
} 
performed, the final corridors investigated are presented in Table 1.

In order to score and determine the route of the bus corridor, different indicators such as total length of the proposed route, special route length index, special route length index / total length, total length index covered, passenger-kilometer index, population index of the covered area, Regional Travel Production Demand Index, Regional Travel Attraction Demand Index, Regional Population Index / Total Length and Travel Production / Total Length and Travel Absorption / Total Length and Plan Horizon Population Production Index and Plan Horizon Travel Production Demand and Travel Horizon Route speed forecast, travel rate improvement index, passenger demand forecast index and auxiliary road index should be examined. Therefore, according to Table 2, each of these indicators was examined in detail.

Decision making, especially when decision criteria are quantitative and qualitative criteria, is one of the most complex topics in engineering and operational research. There are different methods for making decisions, depending on the amount of data, their type, number, and conditions of decision-makers. Among these, AHP hierarchical analysis process method is one of the strongest and most widely used methods in quantitative and qualitative multi-criteria decisions. Because the mathematical framework of this method is a bit complicated, Expert Choice software has been developed to solve this type of problem.

Table 1. Final corridors investigated for BRT lane

\begin{tabular}{cccc}
\hline Corridor No. & Name & Corridor No. & Name \\
\hline 1 & Shahrdari-Janbazan & 2 & Sa'di ped. St.-Valiasr Sq. \\
3 & North-East Ring & 4 & Heshmat Sq.-Bahonar St. \\
5 & Shahrdari-Taleshan Bridge & 6 & East-South Ring \\
7 & Valiasr Sq.-Gil Sq. & $8-1$ & Lakani-Taleshan \\
$8-2$ & Lakani-Shiun & 9 & Sabze Meidan-Shohada \\
10 & Taleghani-Shiun & 11 & Ring Road \\
12 & Central Ring & & \\
\hline
\end{tabular}

Table 2. Examined indexes in different routes

\begin{tabular}{|c|c|c|c|c|c|c|c|c|c|c|c|c|c|}
\hline Index & No. 1 & No. 2 & No. 3 & No. 4 & No. 5 & No. 6 & No. 7 & No. $8-1$ & No. $8-2$ & No. 9 & No. 10 & No. 11 & No. 12 \\
\hline $\begin{array}{l}\text { Proposed Route } \\
\text { Length }\end{array}$ & 7800 & 12100 & 11785 & 10100 & 10450 & 9540 & 22200 & 9700 & 7030 & 16960 & 8800 & 17930 & 8517 \\
\hline $\begin{array}{l}\text { Special Route } \\
\text { Length }\end{array}$ & 3181 & 7930 & 9885 & 7200 & 10450 & 9540 & 15130 & 9700 & 7030 & 2536 & 8180 & 17930 & 8517 \\
\hline Average Speed & 24 & 21 & 22.5 & 18 & 21 & 21 & 20 & 21 & 18.5 & 14.5 & 18.5 & 19.5 & 19.5 \\
\hline Predicted Speed & 35 & 40 & 46 & 41 & 50 & 50 & 40 & 50 & 50 & 20 & 48 & 50 & 50 \\
\hline Speed Improvement & 11 & 19 & 23 & 23 & 29 & 29 & 20 & 29 & 32 & 5 & 29 & 31 & 31 \\
\hline Region Population & 52671 & 76485 & 110268 & 31126 & 97407 & 101519 & 107362 & 76994 & 88095 & 28081 & 110289 & 242247 & 51817 \\
\hline $\begin{array}{c}\text { Future Predicted } \\
\text { Population }\end{array}$ & 83115 & 120693 & 174003 & 49117 & 203710 & 160197 & 169417 & 171497 & 139014 & 44312 & 188238 & 382266 & 81767 \\
\hline Population/Length & 6 & 6 & 9 & 3 & 9 & 11 & 5 & 8 & 13 & 2 & 14 & 14 & 6 \\
\hline $\begin{array}{c}\text { Region Travel } \\
\text { Production Demand }\end{array}$ & 86001 & 131327 & 183106 & 54692 & 144980 & 161620 & 182748 & 114086 & 123844 & 44265 & 168698 & 376730 & 84679 \\
\hline $\begin{array}{c}\text { Region Travel } \\
\text { Absorption Demand }\end{array}$ & 195367 & 198740 & 266473 & 224650 & 290539 & 335256 & 315831 & 73708 & 102456 & 63279 & 127445 & 264248 & 138317 \\
\hline $\begin{array}{c}\text { Travel } \\
\text { Prodution/length }\end{array}$ & 11 & 11 & 16 & 5 & 14 & 17 & 8 & 12 & 18 & 3 & 19 & 21 & 10 \\
\hline $\begin{array}{c}\text { Travel } \\
\text { Absorption/length }\end{array}$ & 25 & 16 & 23 & 22 & 28 & 35 & 14 & 8 & 15 & 4 & 14 & 15 & 16 \\
\hline $\begin{array}{c}\text { Future Travel } \\
\text { Production Demand }\end{array}$ & 135710 & 207234 & 288941 & 86305 & 238778 & 255036 & 288376 & 190028 & 195426 & 69850 & 266205 & 594480 & 133623 \\
\hline $\begin{array}{c}\text { Future Travel } \\
\text { Absorption Demand }\end{array}$ & 308289 & 313612 & 420494 & 354498 & 468471 & 529034 & 498381 & 126311 & 161676 & 99854 & 201108 & 416983 & 218264 \\
\hline $\begin{array}{c}\text { passenger demand } \\
\text { forecast }\end{array}$ & 14068 & 16503 & 22479 & 13967 & 21776 & 24844 & 24929 & 9390 & 11315 & 5377 & 14807 & 32049 & 11150 \\
\hline $\begin{array}{c}\text { No. of Auxiliary } \\
\text { Road }\end{array}$ & 70 & 73 & 93 & 53 & 90 & 64 & 126 & 88 & 94 & 50 & 99 & 192 & 0 \\
\hline
\end{tabular}


The steps for making a decision using a hierarchical process are as follows:

- Building a hierarchical model

- Creating group decision-making capabilities to the model

- Two-by-two comparison of criteria and sub-criteria to determine their importance in decision making

- Synthesis and integration to determine the best options

- Performing sensitivity analysis

In order to determine the best choice, after creating the hierarchy, the elements were evaluated by pairwise comparison. For pairwise analysis between indicators, a questionnaire was distributed among traffic safety experts first and then using data scores for each indicator, EC software was performed between effective indicators. In order to increase the accuracy and efficiency of the model, all indicators affecting the prioritization of the construction of special lines have been applied.

Figure 1 shows the results of the construction of special routes based on different indicators and according to the applied weight. The results of this figure show that the values and priorities of each section are different based on the considered indicators. For example, corridors No. 11, 10,7 , and 8-1 have a high score in terms of specific lane lengths. If in the travel absorption ratio index, Corridor No. 6 with a score of 0.110 has the highest score. Also, Corridor No. 1 has a high score in the priority of constructing special routes only in terms of average speed, and in other indicators is not good.

Finally, by combining effective indicators using EC software, final results of the AHP model for prioritizing the construction of special routes were obtained. As shown in Figure 2, corridor No. 11 with a score of 0.694 and with a large difference from others, receives the highest score. Also in this analysis, corridors No. 6 and 3 with scores of 0.462 and 0.442 , respectively, have the second and third ranks of correction priority. In this analysis, corridor number 9 with a score of 0.057 has the lowest potential for constructing a BRT route.

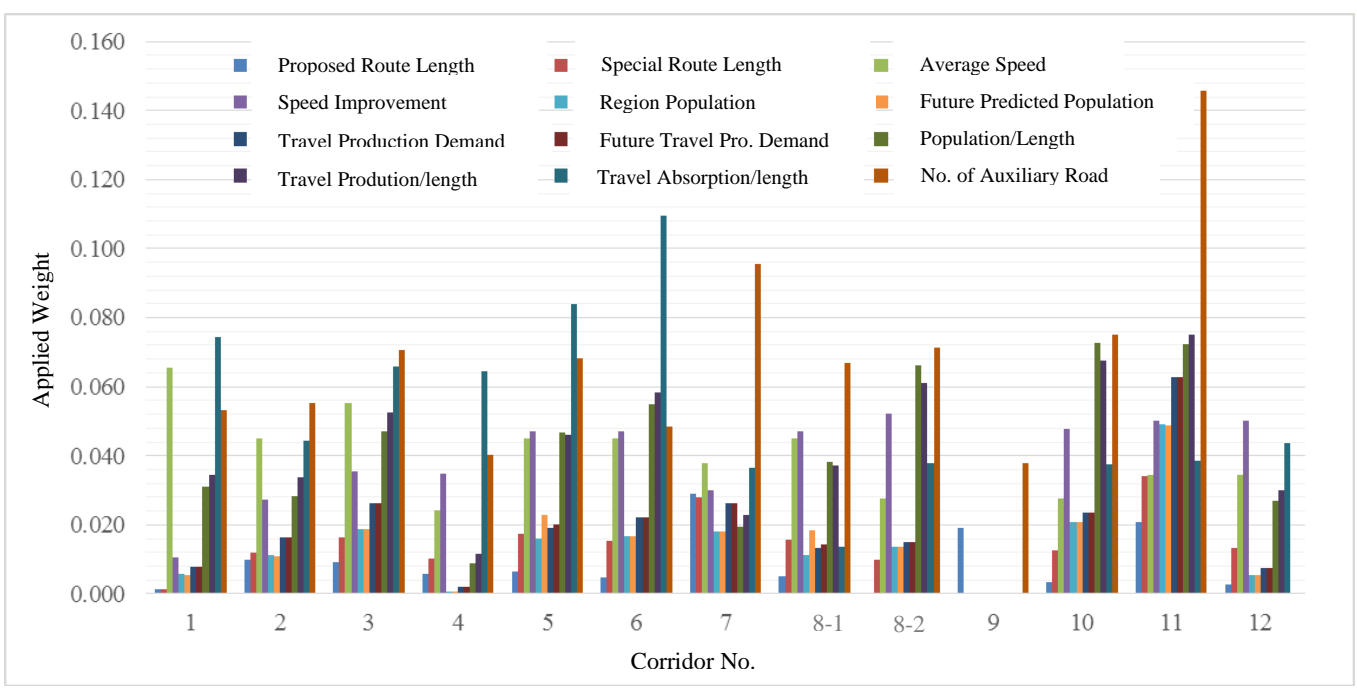

Figure 1. Results of special routes prioritization parameters based on different indicators and applied weights

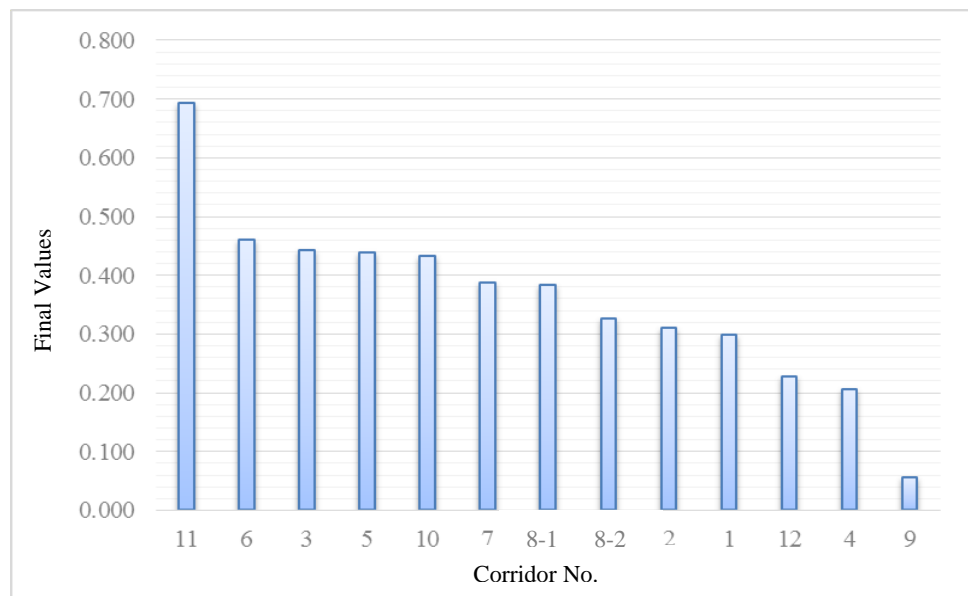

Figure 2. Final results of AHP model to prioritize the construction of special routes

After reviewing and comparing the objectives in measuring the construction of different special BRT routes, to provide a comprehensive model for evaluating and prioritizing the construction, the linear hierarchical-fuzzy 
method has been used. Thus, at first, using expert opinions, the importance coefficients of objectives, indicators and sub-indicators were determined. Then by preparing the desired forms using the AHP method, a survey of 30 transport and traffic experts was conducted. After analyzing the expert opinions using EC software, the coefficients of importance for the objectives, index and sub-index are determined in Table 3.

After determining the significance coefficients using the hierarchical method and the values of the sub-indices using the linear fuzzy function, the public transport status in the specified objectives was determined. Figure 3 shows the status of different corridors based on geometry, speed, and passenger volume. In this figure, the correction prioritization indices are scored in the range of $1-0$, that score of 1 indicates the highest priority, and a score of zero indicates the lowest priority.

Finally, after reviewing and evaluating the public transportation indicators of different sections, Figure 4 shows the final results of the Special routes and BSIP. The results of the final model show that the priority of correcting corridor No. 11 with an index of about 0.297, had the highest construction priority among different corridors. After that, corridor No. 7 with index 0.228 and No. 5 with index 0.201 are in the second and third ranks, respectively. After these three routes, routes 8-1,3,10, 8-2 and 6 are in the fourth to eighth ranks, respectively, and their BSIP index is higher than the average value. Also, route No. 9 with BSIP index equal to 0.055 has the lowest construction priority among different routes.

Table 3. Software output results to determine significance coefficients for objectives, indexes and sub-indexes

\begin{tabular}{|c|c|c|c|c|c|}
\hline Objective & Objective Score & Index & Index Score & Sub-index & Sub-index Score \\
\hline \multirow{3}{*}{ Geometric } & \multirow{3}{*}{0.215} & \multirow{3}{*}{ Route Dimensions } & \multirow{3}{*}{1} & Proposed Route Length & 0.26 \\
\hline & & & & Special Route Length & 0.20 \\
\hline & & & & No. of Auxiliary Road & 0.54 \\
\hline \multirow{2}{*}{ Speed } & \multirow{2}{*}{0.240} & \multirow{2}{*}{ Route Speed } & \multirow{2}{*}{1} & Average Speed & 0.53 \\
\hline & & & & Speed Improvement & 0.47 \\
\hline \multirow{7}{*}{ Passenger volume } & \multirow{7}{*}{0.545} & \multirow{3}{*}{ Population } & \multirow{3}{*}{0.390} & Region Population & 0.23 \\
\hline & & & & Future Predicted Population & 0.30 \\
\hline & & & & Population/Length & 0.47 \\
\hline & & \multirow{4}{*}{ Demand } & \multirow{4}{*}{0.610} & Travel Production Demand & 0.20 \\
\hline & & & & Future Travel Pro. Demand & 0.21 \\
\hline & & & & Travel Prodution/length & 0.26 \\
\hline & & & & Travel Absorption/length & 0.33 \\
\hline
\end{tabular}

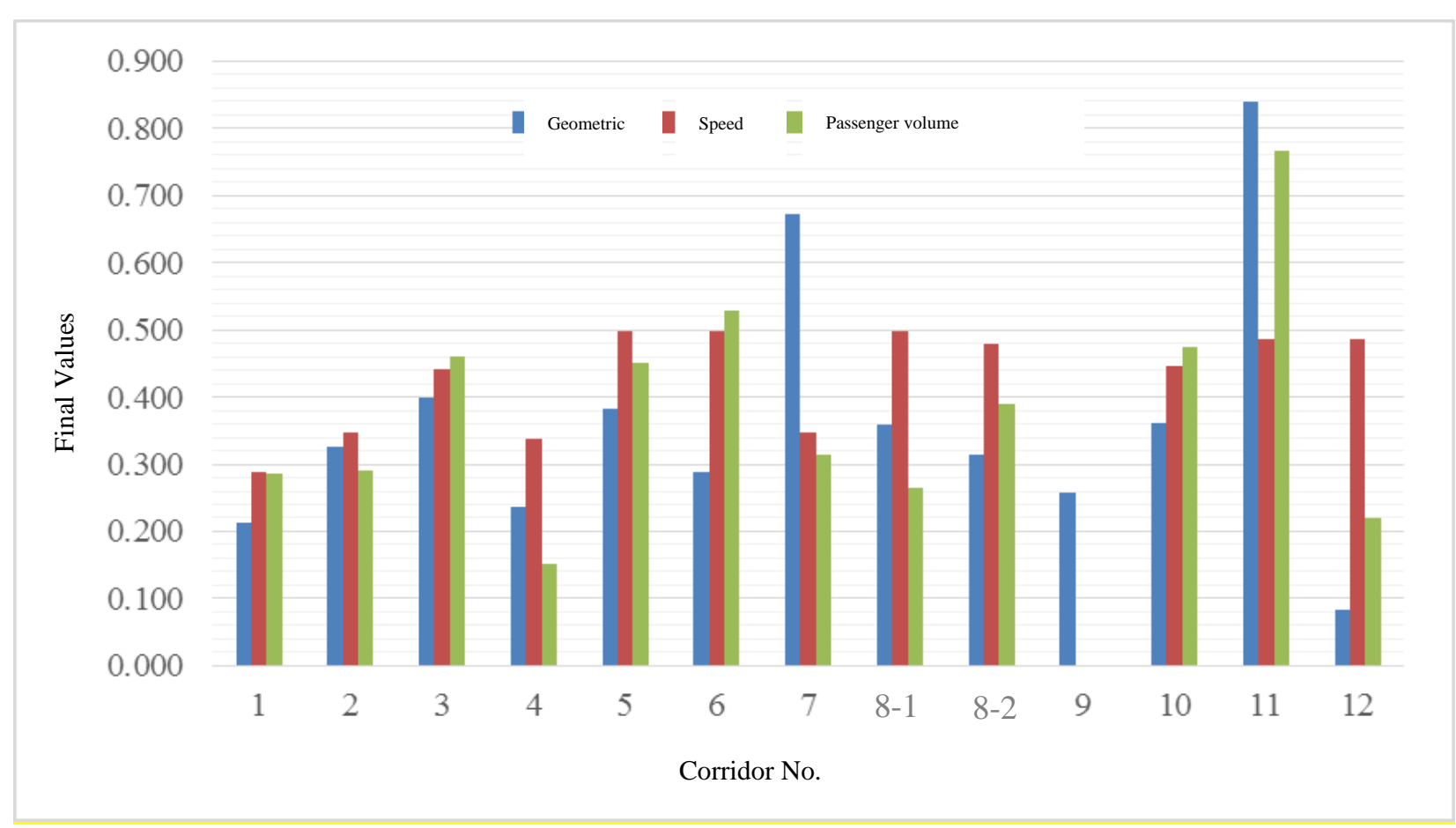

Figure 3. Status of different corridors based on geometric, speed and passenger volume 


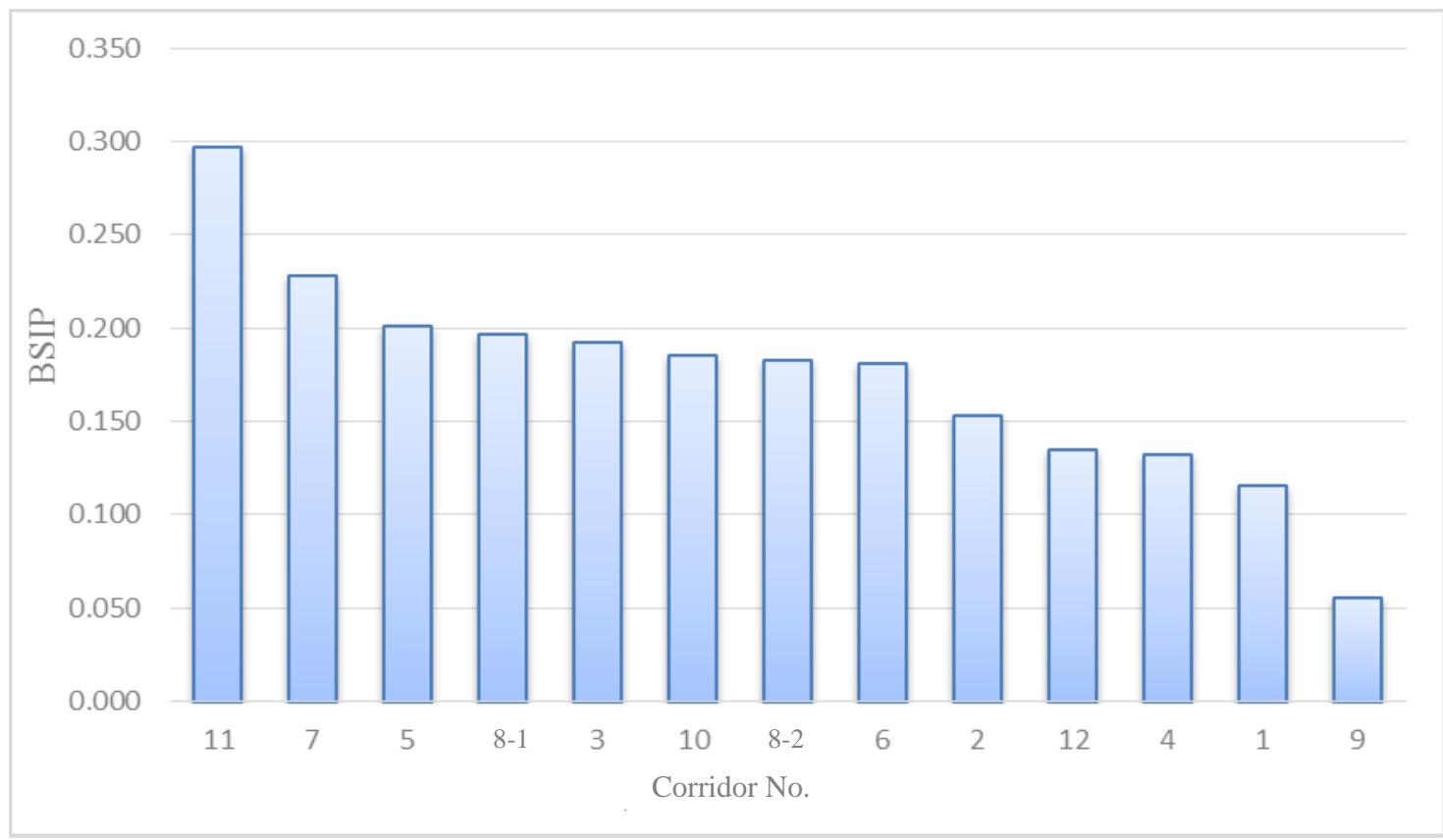

Figure 4. Final result of the route evaluation and prioritization model (BSIP)

\section{Conclusion}

In this study, the importance of special bus routes has been expressed and it was pointed out that the proper development of these routes can increase the level of access of people to stations, increase access from stations to major travel centers, shorten travel time, increase travel speed and ultimately increase desire to use public transport. So it reduces the use of private cars, traffic flow, delays and accidents in Rasht. Therefore, all $220 \mathrm{~km}$ of streets in Rasht in the form of 13 corridors were examined using AHPFuzzy analysis method and special BRT routes were prioritized. According to the results of studies, the Ring Road of Rasht is the first priority for construction. The route of Vali Asr Square to Gil Square (radial ring) is in the second priority and Shahrdari Square to Janbazan Square (radial ring) is in the third priority.

\section{References}

[1] H. Hariri Asli, M. Arabani, Y. Golpour, Reclaimed Asphalt Pavement Based on a Geospatial Information System, Slovak Journal of Civil Engineering 28 (2020) 36-42.

[2] Studies on organizing the bus network and feasibility study of special bus routes, Amayesh-e-Sarzamin Research Group, 2012.

[3] I. Bargegol, V. Najafi Moghaddam Gilani, Estimating Delay of Vehicles in Nearside Legs of the Signalized Intersections under Expectation Method in Under-Saturation Conditions for Isolated Intersection, Trends Journal of Sciences Research 4 (2015) 121-125.

[4] H. Levinson, Analyzing Transit Travel Time Performance, Transportation research record 915 (1983) 1-6.

[5] A. Saka, Model for Determining Optimum Bus-Stop Spacing in Urban Areas, Journal of Transportation Engineering 127 (2001).

[6] B. Yu, Zh. Yang and J. Yao, Genetic Algorithm for Bus Frequency Optimization, Journal of Transportation Engineering 136 (2010) 576-583.

[7] H. Assarzadegan, A. Nadeali, M. Ataie, R. Pourmiri, Optimal location of BRT stations using Arc Gis software and AHP and
TOPSIS techniques, $11^{\text {th }}$ International conference on traffic and transportation engineering, Tehran, Iran, 2103.

[8] M. Rastbod, I. Bargegol, R. Vatani, Optimizing the distance between bus stops and their number by multi-objective genetic algorithm to reduce passenger travel time, $1^{\text {st }}$ national conference on development of civil engineering, architecture, electricity and mechanics, Gorgan, Iran, 2015

[9] Sh. Abedi, Optimal location of bus stations with the help of big data technology, Ms.C. thesis, University of Semnan, 2016.

[10] H. Varesi, Gh. Shiran, H. Azizi, Location of bus stations with ANP model and fuzzy logic in GIS (Case study: Khorramabad city), Journal of Urban Research and Planning 23 (2016).

[11] A. Jamili, M. Pourseyed Aghaee, Robust stop-skipping patterns in urban railway operations under traffic alteration situation, Transportation Research Part C 61 (2015) 63-74.

[12] A. Gumus, Evaluation of hazardous waste transportation firms by using a two-step fuzzy-AHP and TOPSIS methodology, Expert Systems with Applications 36 (2009) 4067-4074.

[13] M.A. Badri, A combined AHP-GP model for quality control systems, International Journal of Production Economics 72 (2001) 27-40. 